\title{
Influence of smoking on postpartum depression in Japan
}

\author{
Atsuko Satoh ${ }^{1 \#}$, Chiaki Kitamiya ${ }^{2}$, Yukoh Yaegashi ${ }^{3}$, Fujiko Ohse ${ }^{4}$, Sangun Lee $^{5}$, \\ Chikako Kishi $^{6}$, Kazuko Menzawa ${ }^{7}$, Hidetada Sasaki ${ }^{8}$ \\ ${ }^{1}$ Hirosaki University of Health and Welfare, Aomori, Japan; ${ }^{\#}$ Corresponding Author: a-satoh@,jyoto-gakuen.ac.jp \\ ${ }^{2}$ Hirosaki University Graduate School of Health Sciences, Aomori, Japan \\ ${ }^{3}$ Tohoku Computer College, Aomori, Japan \\ ${ }^{4}$ Akita University of Nursing and Welfare, Akita, Japan \\ ${ }^{5}$ Department of Physical Therapy, Aomori University of Health and Welfare, Aomori, Japan \\ ${ }^{6}$ Kensei Hospital, Hirosaki, Japan \\ ${ }^{7}$ Hirossaki University, Hirosaki, Japan \\ ${ }^{8}$ Sendai Tomizawa Hospital, Sendai, Japan
}

Received 4 June 2013; revised 5 July 2013; accepted 31 July 2013

Copyright (C) 2013 Atsuko Satoh et al. This is an open access article distributed under the Creative Commons Attribution License, which permits unrestricted use, distribution, and reproduction in any medium, provided the original work is properly cited.

\section{ABSTRACT}

Aim: To investigate the influence of smoking on postpartum depression. Methods: One thousand fifty-one women, in a rural city in Aomori Prefecture, Japan, prospectively fulfilled the selection criteria and completed self-reporting questionnaires on postnatal depression at 5 - 6 days, 1 month, 4 months, 7 months and 12 months after childbirth, using the Edinburgh Postnatal Depression Scale (EPDS) and a life and social events scales including smoking habits. Results: Seven hundred seventy-seven women were nonsmokers. Among two hundred seventy-four women who were smokers before becoming pregnant (26\% of pregnant women), 241 women quit smoking during pregnancy and 33 women continued smoking. Smoking habits were significantly associated with sociopsychological states and we found that EPDS scores of smokers were significantly higher than EPDS of non-smokers. The EPDS scores of both non-smokers and smokers were higher at 5 - 6 days, but were stable from 1 month to 12 months, after childbirth. Fifty-one women who quit smoking after childbirth resumed smoking during the 1 - 12 month periods after childbirth. The EPDS scores of $\mathbf{5 1}$ women who resumed smoking were significantly reduced after they resumed smoking. Conclusion: The EPDS scores of smokers were higher than those of non-smokers and a smok-

\footnotetext{
${ }^{*}$ Conflict of interest: We declare no conflict of interest.
}

ing habit may help to alleviate postpartum depression.

Keywords: Smoking Habit; Stress; Childbirth; Edinburgh Postnatal Depression Scale;

Sociopsychological State

\section{INTRODUCTION}

Many smokers are unable or unwilling to give up smoking, despite it being linked with serious disease in numerous studies [1-5]. Smoking habits may be influenced by mental disorders, including anxiety and depression [6], increased level of actual or perceived stress [7], reducing stress $[8,9]$, or abuse-related post-traumatic stress disorder [10], and so on. Such factors suggest that, the effects of smoking on mental disorders have not been consistently reported, probably due to subtle effect on psychological performances in normal persons. Postpartum depression is thought to be a crisis period of woman's life cycle because of a combination of physiological factors (e.g. rapid changes in the level of hormones in the body), psychological factors (e.g. worries about childbirth and child care), and social factors (e.g. support systems for pregnant and parturient women) [11]. The prevalence of this disorder and its devastating consequences for the mother mean that postpartum depression has a significant public impact, and identifying the risk factors for postnatal depression is one of the major challenges of importance. As the postnatal period is known as one associated with the likely onset of mental health problems, it may therefore be more appropriate for a study on the 
effects of smoking on mental disorders.

In the present study, postnatal depression has been assessed using the Edinburgh Postnatal Depression Scale (EPDS) [12] and we examine how smoking habit might modify mental disorder in postnatal depression. To date, this is the first study to investigate effect of smoking on postpartum depression using the EPDS.

\section{METHODS}

We prospectively studied 1123 women who gave birth in a rural city in Aomori Prefecture, in the northern part of Japan (population: 174,000; number of birth from 2009 April to 2013 January: 4735), and who brought their infant for a check-up at 5 - 6 days after delivery at six different obstetrics departments. We did not include mothers who suffered from psychotic disorders and had consulted a psychiatrist. Mothers who had babies with a birth weight of $<2000 \mathrm{~g}$ were also excluded from the study as they directly consulted pediatricians. Answers were obtained using self-reported questionnaires from women who agreed to participate in the study using selfreported questionnaires. One thousand fifty-one women, out of 1123 women approached, completed questionnaires at 5 - 6 days after childbirth, and were prospectively followed up at 1, 4, 7 and 12 months and adopted in the present analysis.

The EPDS, which has been used previously to screening for postpartum depression [12], is a 10-item selfreporting scale that seems to be especially valid for use with child-bearing women and it is highly effective from the viewpoint of sensitivity and specificity [13]. Each item is scored on four-point scale from $0-3$, with the minimum and maximum total scores being 0 and 30 points, respectively. A Japanese version of the EPDS was used in the present study [14].

To ascertain the sociopsychological state of childrearing burnout of postpartum depression, four different kinds of questionnaire were asked regarding: first, social status: (age, educational level, and annual income), second, obstetric factors: (previous childbirth experience, i.e. (primiparas and multiparas), premature birth and/or abortion, the baby's weight at delivery and breast feeding or bottle feeding), third, physical status: (worries concerns baby care, smoking habit, smoking of both parents, and alcohol consumption), fourth, sociability: (playing a pinball game (pachinko), likelihood of communicating with others, a good relationship with husband, satisfied with childcare, and financial concerns). To confirm differences between the basic psychological characteristics of anxiety between smokers and non-smokers, a State Trait Anxiety Inventory (STAI) [15] was carried out by mail at one and a half years and 2 years after delivery, respectively.
The study protocol adhered to the recommendations of the Declaration of Helsinki (World Medical Association, 2000). Verbal informed consent was obtained and the participants' anonymity was preserved by the use of a coding system. Ethical approval was obtained from the Ethical Committee at Akita Nursing and Welfare University, Japan. The statistical differences of the sociopsychological state between of smokers and non-smokers were calculated by the Chi-square test. Multivariate regression was used for the EPDS versus sociopsychological state, where EPDS and age were entered as a continuous independent variable, with a level of educational level lower than high school and more higher than university corresponding to 1 and 2 , yearly income of $<300$, $300-500$ and $>500$ million yen corresponding to 1,2 and 3 , primiparas and multiparas corresponding to 1 and 2 , experience of abortion (of yes and no) corresponding to 1 and 2 , baby weight of $<2500 \mathrm{~g}$ and $>2500 \mathrm{~g}$ corresponded to 1 and 2, worries about baby care (of yes and no) corresponded to 1 and 2, smoker and non-smoker corresponding to 1 and 2, smoking habit of husband (of yes and no) corresponding to 1 and 2, habit of alcohol intake before pregnancy (of yes and no) corresponded to 1 and 2, activities of communication with others (of yes and no) corresponded 1 and 2, and worries about financial status (of yes and no) corresponded to 1 and 2, respectively. The statistical differences of EPDS and the State Trait Anxiety Inventory between smokers and nonsmokers were determined by using the Mann-Whitney's U-test, respectively. Two-way ANOVA was performed for the EPDS scores between smokers and non-smokersand, where a significant difference was found with the ANOVA, Tukey's test was used for the individual parameters. Differences between data obtained before and after resumption of smoking were assessed using the Wilcoxson signed-rank test. The data were expressed as means $\pm \mathrm{SD}$, with the differences were regarded as statistically significant at $p<0.05$.

\section{RESULTS}

Significant differences of the sociopsychological states between non-smokers $(\mathrm{n}=777)$ and smokers $(\mathrm{n}=274$, $26 \%$ of mothers) completing questionnaires at 5 - 6 days after childbirth are shown in Table 1. Smokers were of younger age, were less well educated state, had a lower yearly income, more primiparas, and were more likely to have a premature birth and/or abortion. Their babies were of lower baby weight, their husbands were more likely to smoking habit, and they drank more frequently alcohol. In addition, smokers played pinball (pachinko) more frequently, were less activities to communicate anybody, lower activities to talk with anybody, and had more worries about their financial situation than non- 
Table 1. Socialpsychological states of smokers and non-smokers.

\begin{tabular}{|c|c|c|c|c|}
\hline & & Non-smokers & Smokers & \\
\hline & & $\mathbf{N}=777$ & $N=274$ & $\boldsymbol{P}$ \\
\hline \multirow[t]{4}{*}{ Age (years) } & $>10$ & 5 & 6 & 0.000 \\
\hline & $29-20$ & 325 & 165 & \\
\hline & $39-30$ & 422 & 110 & \\
\hline & $49-40$ & 25 & 3 & \\
\hline \multirow[t]{3}{*}{ Education } & High school & 297 & 148 & 0.000 \\
\hline & University & 480 & 124 & \\
\hline & Unknown & $\mathbf{0}$ & 2 & \\
\hline Annual income & $<300$ & 177 & 91 & 0.000 \\
\hline \multirow[t]{3}{*}{ (million yen) } & 301- & 350 & 123 & \\
\hline & 500- & 247 & 55 & \\
\hline & Unknown & 3 & 5 & \\
\hline \multirow[t]{3}{*}{ Delivery } & Primiparas & 323 & 145 & 0.016 \\
\hline & Multiparas & 453 & 129 & \\
\hline & Unknown & 1 & 2 & \\
\hline \multirow{3}{*}{$\begin{array}{c}\text { Experience of } \\
\text { abortion }\end{array}$} & Yes & 241 & 115 & 0.000 \\
\hline & No & 534 & 159 & \\
\hline & Unknown & 2 & $\mathbf{0}$ & \\
\hline \multirow[t]{3}{*}{ Birthweight (kg) } & $<2500$ & 40 & 23 & 0.042 \\
\hline & $>2500$ & 737 & 251 & \\
\hline & Unknown & $\mathbf{0}$ & $\mathbf{0}$ & \\
\hline Worries about & Yes & 150 & 66 & 0.049 \\
\hline \multirow[t]{2}{*}{ baby care } & No & 627 & 204 & \\
\hline & Unknown & $\mathbf{0}$ & 4 & \\
\hline \multirow[t]{3}{*}{ Smoking of husband } & Yes & 406 & 228 & 0.000 \\
\hline & No & 371 & 46 & \\
\hline & Unknown & $\mathbf{0}$ & $\mathbf{0}$ & \\
\hline Alchohol habit & Yes & 471 & 213 & 0.000 \\
\hline \multirow[t]{2}{*}{ before pregnancy } & No & 306 & 61 & \\
\hline & Unknown & $\mathbf{0}$ & $\mathbf{0}$ & \\
\hline Playing pinball & Yes & 78 & 87 & 0.000 \\
\hline \multirow[t]{2}{*}{ before pregnancy } & No & 699 & 187 & \\
\hline & Unknown & $\mathbf{0}$ & $\mathbf{0}$ & \\
\hline Often dislike to & Yes & 151 & 76 & 0.000 \\
\hline \multirow[t]{2}{*}{ have a talk } & No & 625 & 198 & \\
\hline & Unknown & 1 & $\mathbf{0}$ & \\
\hline Worried about & Yes & 202 & 104 & 0.000 \\
\hline \multirow[t]{2}{*}{ income } & No & 574 & 170 & \\
\hline & Unknown & 1 & $\mathbf{0}$ & \\
\hline
\end{tabular}

smokers. Table 2 shows the relative impact of the EPDS scores versus sociopsychological states (smokers, yearly income, experience of delivery, worries about baby care, activities to talk with anybody and worries about financial condition) calculated using multiple logistic regression. Sequential changes of EPDS score and numbers of participants are shown in Figure 1. Two hundred fortyone smokers quit smoking and thirty-three smokers continued smoking during pregnancy. At 5 - 6 days after childbirth, the EPDS scores of non-smokers were significantly lower than both the EPDS scores of smokers who give up smoking $(p<0.01)$ and the scores of smokers with continued smoking $(p<0.001)$, respectively. At 1 month after childbirth, the two groups derived from mothers who smoked during pregnancy (i.e. who quit smoking or continued smoking 5 - 6 days after childbirth, as shown in Figure 1) were each divided into two groups. The "with quit smoking" group was split into those mothers who continued not to smoke (designated group $B$ in Figure 1) and those who resumed smoking (group $\mathrm{C}$ in Figure 1). The group of mothers who continued smoking at 5 - 6 days after childbirth were separated into those who had given up smoking by 1 month after childbirth (group D in Figure 1) and those who continued smoking at 5 - 6 days after childbirth (group E in Figure 1), respectively. The original non-smokers are designated group A in Figure 1. Over the following period up to 12 months, there were further changes as either quit smoking or resumed smoking, according to their previous status and vice versa during 12 months. Figure 2 shows sequential changes of EPDS scores in both smokers and non-smokers over the 12 months of the study. The scores of non-smokers were lower than EPDS score of smokers $(p<0.05)$ and also lower than the scores of group B mothers $(p<0.05)$ (data not shown), respectively. Overall, EPDS scores at 5 - 6 days after childbirth were higher than EPDS scores over the subsequent 1 to 12

Table 2. Multivariable model of the relationship between EPDS and sociopychological states.

\begin{tabular}{lcc}
\hline \multicolumn{1}{c}{ Risk variable } & Regression coefficient & $P$ Value \\
\hline Smoking habit & -0.070 & 0.018 \\
Yearly income & -0.088 & 0.004 \\
Experience of delivery & -0.097 & 0.001 \\
Concern about baby care & -0.131 & 0.000 \\
$\begin{array}{l}\text { Willingness to communicate } \\
\text { with others }\end{array}$ & -0.291 & 0.000 \\
Concern about finance & -0.137 & 0.000 \\
Multiple correlation coefficient $=0.427$, Adjusted $\mathrm{R}^{2}=0.182$
\end{tabular}




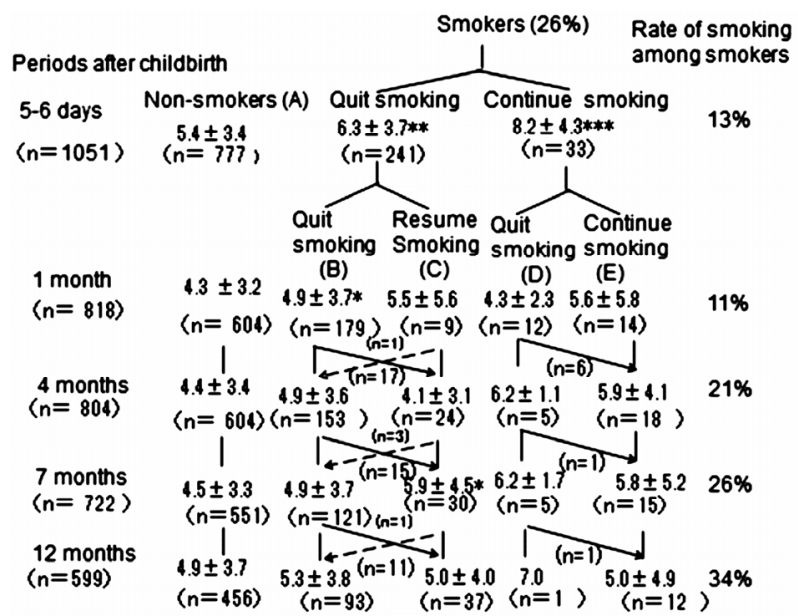

Figure 1. Sequential follow up of EPDS of non-smokers (A) and four groups of smokers after childbirth: those mothers who quit smoking and continued not to smoke (B); those who quit smoking during pregnancy but resumed smoking followed by quit smoking during pregnancy $(\mathrm{C})$; those who continued smoking through pregnancy until 5 - 6 days after childbirth but had not quit smoking by 1 month after childbirth (D); and those who continued smoking during pregnancy throughout the study period (E). Continuous lines show subjects who resumed smoking after quitting smoking $(\mathrm{n}=51)$ and dotted lines show opposite situation $(\mathrm{n}=4) .{ }^{*}(p<0.05),{ }^{* *}(p<0.01)$, and ${ }^{* * *}(p<$ $0.001)$ show statistical differences in EPDS scores between the $\mathrm{A}$ and $\mathrm{B}, \mathrm{C}, \mathrm{D}$ and $\mathrm{E}$ groups, respectively.

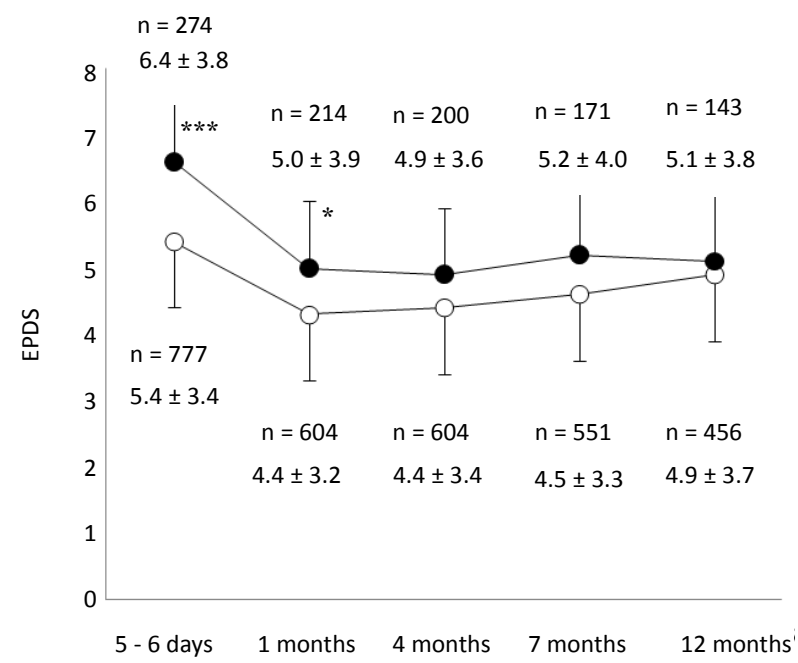

Figure 2. Sequential changes in EPDS scores of smokers $(\bullet)$ and non-smokers $(0)$, respectively. ${ }^{*}(p<0.05)$ and ${ }^{* * *}(p<$ $0.001)$ show statistical differences between smokers and nonsmokers at $5-6$ day and 1 month, respectively. $\S \S(p<0.001)$ shows statistical differences between EPDS scores at 5 - 6 days and $1,4,7$, and 12 months in both smokers and non-smokers, respectively.

months in both smokers and non-smokers, respectively $(p<0.001)$. There were no systematic variables of EPDS from 1 to 12 months after childbirth in both smokers and non-smokers. Of those mothers whose EPDS score re- mained stable over 1 - 12 month period following childbirth, fifty one changed status from quit smoking to resumed smoking: for the participants who resumed smoking, a change in EPDS score was noted (Figure 3). There was significant decrease in EPDS scores in those mothers who after resumed smoking than compared to those remaining in the "quit smoking" category $(p<0.001)$. A change from breast feeding to bottle feeding was the only factor of sociophysiological state to show a significant difference in the 51 mothers who resumed smoking from quit smoking $(p<0.01)$, but there were no relationships between bottle feeding and EPDS score among either non-smokers and/or smokers as a whole (data not shown). Continuous follow up during 1.5 and 2 years after delivery showed no systematic differences in STAI between smokers and non-smokers for either State and/or Trait Anxieties, respectively (Table 3).

\section{DISCUSSION}

The numbers of conflicting results come out about the effects of smoking on stress. Smokers will suffer from increased stress when they quit smoking [8]. This model states that smokers are calmed by smoking, yet they report high levels of stress [9]. On the other hand, longitudinal studies have demonstrated that giving up smoking leads to reduced feeling of stress [7]. Cessation of smoking will lead to a period of increased stress, followed by a return to baseline, because acute nicotine deprivation

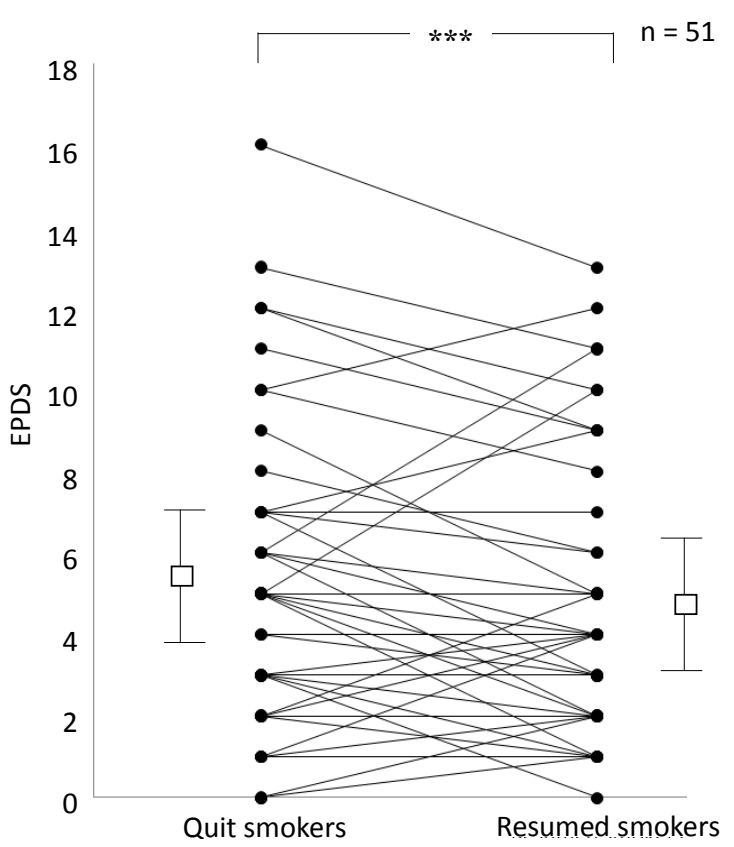

Figure 3. Changes in EPDS scores from quit smoking to resumed smoking from 1 to 12 months after childbirth (n $=51$ ). Means $\pm \mathrm{SD}$ are shown by open squeal and bars, respectively. ${ }^{* * *}(p<0.001)$ shows statistical difference between quit smoking and resumed smoking categories. 
Table 3. State Trait Anxiety Inventory (STAI) Score of smokers and non-smokers at 1.5 years and 2 years after delivery.

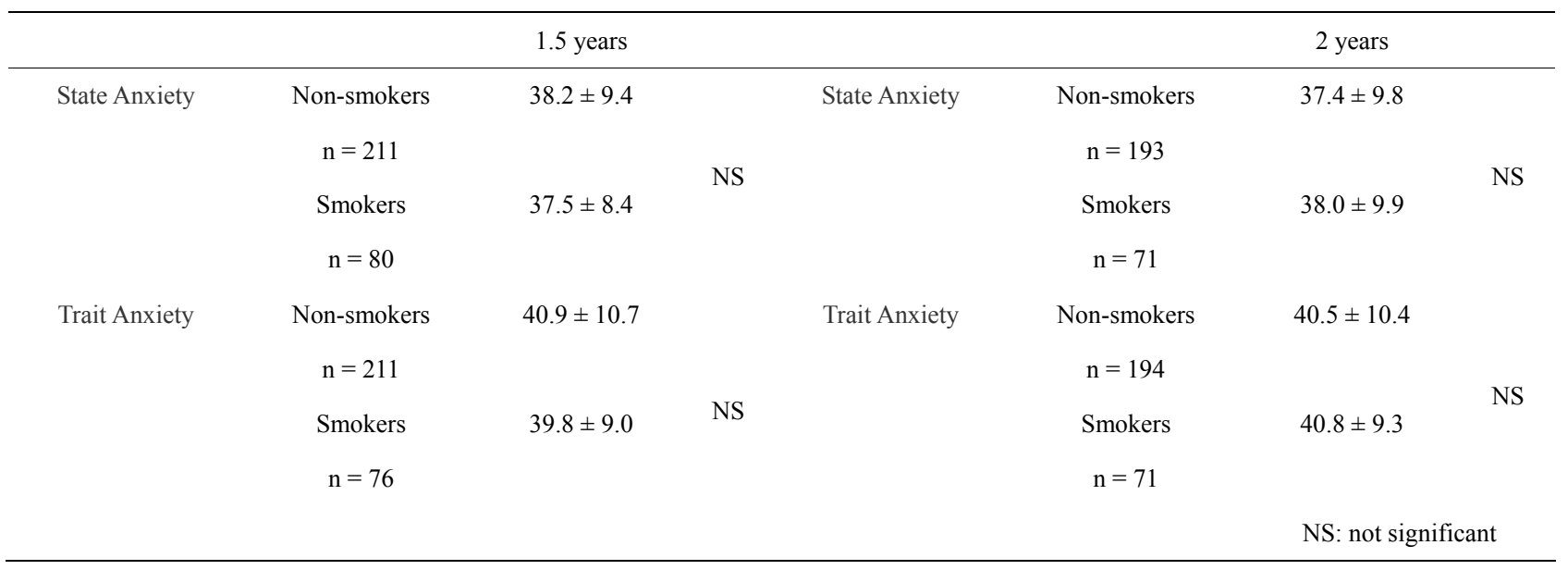

(i.e. between cigarettes) is stressful. Then, the former smoker no longer suffers from the adverse mood effects of acute nicotine depletion. However, it has not been established whether or not quitting smoking leads to reduced stress or not in terms of sociopsychological status of individual; for example, a person experiencing a stressful sociopsychological states smokers might not be reduced stress level even after long term cessation of smoking. Thus, it has been reported that as compared to nonsmokers of mothers, smokers of mothers who have exhibited a more stressful sociopsychological state (higher levels of perceived stress, depression, neuroticism, and negative paternal support) were associated with rate of being a smoker than a non-smoker [16]. Smokers differed from non-smokers in all demographic risk factors, including of being African American, being pregnant as a teenager, having lower income and less education, and living in high-crime areas [8]. Our data showed that high EPDS scores were associated with smoking, income, anxiety about children, and multiparas. Higher EPDS scores were observed in smokers during the year after following childbirth. Even after quitting smoking, EPDS scores of former smokers remained higher than EPDS scores of non-smokers after delivery. During prospective follow up using EPDS, we found that among smokers, a certain numbers of mothers changed from quit smoking to resume smoking and their EPDS scores subsequently decreased after resumed smoking in these mothers. Despite this effect, such mothers would be expected to smoke to reduce EPDS but a relatively elevated EPDS score would not be lightened unless their sociopsychological states being improved.

This is the first prospective report of the effect of smoking on postpartum depression using EPDS. Of mothers in rural area of northern part of Japan, 21\% were smokers, which was about double of the average rate for young Japanese women [17]. Among smokers of mothers who smoked, $13 \%$ continued smoking after pregnancy and the percentages of smoking were $11 \%, 21 \%, 26 \%$, and increased up to $34 \%$ at $1,4,7$, and 12 months, respectively. It might be the case that smoking would decrease stress for mothers experiencing postpartum depression and, if so, the number of smokers would be expected to increase during one year following childbirth $[18,19]$. It is a serious challenge to decrease rate of smoking among mothers and thereby reduce the health risks to mothers themselves and prevent various influrnces on their children [20,21]. One strategy would be to ameliorate sochiopsychological state factors $[22,23]$, and other might be to develop handy novel replacement to tolerate stress which could be used freely, for example, handy harmless tobacco, similar to non-alcohol beer for alcoholism, because there are too many smokers to treat with medicines like nicotine patches [24] or nicotine replacement therapy [25]. Mothers who resumed smoking were associated with a switch to bottle feeding from breast feeding, which suggested smoking offered a means of relaxation from the stress of caring, feeding and not being able to go outside the home (because as mothers who smoke did not tend to favor to communicate with socialize). Husbands of smokers were more frequently smoked, which increased temptation of mothers to smoke, and therefore if the husband could also quit smoking, the mothers would be successful in giving up smoking herself $[26,27]$. Work style (i.e. shift work) was critically associated with cigarette smoking in Japanese female workers [28]. Reducing the stress of caring for the baby might also allow mothers to avoid smoking, because when husband's cooperation is more involved in baby care, EPDS scores are lower [29]. Alcohol consumption is also correlated with smoking and therefore avoiding alcohol might help mothers to quit smoking [30,31].

One of the potential limitations of the present study was that smokers and non-smokers exhibited differences 
of behavior and personality; for example, because smokers were reported to be heterogeneous in terms of psychoticism [32]. However, we found that both State and Trait Anxiety scores of smokers did not different significantly from those of non-smokers and, moreover, behavior and personality would not be a factor to a difference in EPDS results between smokers and nonsmokers. The numbers of participants were sequentially decreased over the period of the study, which might affect the results. However, rates of sequentially decreased numbers of subjects were similar between smokers and non-smokers, which would bring similar results as all participants completed. Ninety-four percent of subjects agreed to participate, which suggested enough quality of protocol of the present study to analysis.

\section{ACKNOWLEDGEMENTS}

This work was supported by a grant from the Smoking Research Foundation. We do gratefully acknowledge Kuroishi Hospital in Aomori Prefecture for assistance in preparation of this study.

\section{REFERENCES}

[1] Sakata, R., McGale, P., Grant, E.J., Ozasa, K., Peto, R. and Darby, S.C. (2012) Impact of smoking on mortality and life expectancy in Japanese smokers: A prospective cohort study. British Medical Journal, 345, e7093. doi:10.1136/bmj.e7093

[2] Pirie, K., Peto, R., Reeves, G.K., Green, J. and Beral, V. (2013) The 21st century hazard of smoking and benefits of stopping: A prospective study of one million women in the UK. Lancet, 12, 133-141.

[3] Yamaya, M. (2012) Chronic obstructive pulmonary disease and severe pneumonia. Geriatrics Gerontology International, 12, 177-179. doi:10.1111/j.1447-0594.2011.00832.x

[4] Fujii, M., Iwakami, S., Takagi, H., Itoigawa, Y., Ichikawa, M., Iwakami, N., Ishiwata, T., Seyama, K. and Takahashi, K. (2012) Factors influencing weaning from mechanical ventilation in elderly patients with severe pneumonia. Geriatrics Gerontology International, 12, 277-283. doi:10.1111/j.1447-0594.2011.00765.x

[5] Wakabayashi, R., Motegi, T., Yamada, K., Ishii, T., Jones, R.C., Hyland, M.E., Gemma, A. and Kida, K. (2011) Efficient integrated education for older patients with chronic obstructive pulmonary disease using the lung information needs questionnaire. Geriatrics Gerontology International, 11, 422-430.

[6] Bruijinzeel, A.W. (2011) Tobaco addiction and the dysregulation of brain stress systems. Neuroscience and Biobehavioral Reviews, 36, 1418-1441. doi:10.1016/j.neubiorev.2012.02.015

[7] Parrott, A.C. (1995) Smoking cessation leads to reduced stress, but why? International Journal of Addictions, 30, 1509-1516.

[8] Slopen, N., Dutra, L.M., Williams, D.R., Mujahid, M.S.,
Lewis, T.T., Bennett, G.G., Ryff, C.D. and Albert, M.A. (2012) Psychosocial stressors and cigarette smoking among African American adults in midlife. Nicotine and Tobacco Research, 14, 1161-1169. doi:10.1093/ntr/nts011

[9] Cohen, S. and Lichtenstein, E. (1990) Perceived stress, quitting smoking, and smoking relapse. Health Psychology: Official Journal of the Division of Health Psychology, American Psychological Association, 9, 466-478.

[10] Lopez, W.D., Konrath, S.H. and Seng, J.S. (2011) Abuserelated post-traumatic stress, coping, and tobacco use in pregnancy. Journal of Obstetric, Gynecologic, and Neonatal Nursing, 40, 422-431.

[11] Satoh, A., Kitamiya, C., Kudoh, H., Watanabe, M., Menzawa, K. and Sasaki, H. (2009) Factors associated with late post-partum depression in Japan. Japan Journal of Nursing Science, 6, 27-36. doi:10.1111/j.1742-7924.2009.00121.x

[12] Cox, J. L., Holden, J. M. and Sagovsky, R. (1987) Detection of postnatal depression. Development of the 10-item Edinburgh Postnatal Depression Scale. British Journal of Psychology, 150, 780-786.

[13] Cox, J.L. (1994) Origin and development of the 10-item Edinburgh Postnatal Depression scale. In J. L. Cox and J. Holden, Eds., Perinatal Psychiatry, Gaskell, London, 115-124.

[14] Okano, T., Murata, M., Masuji, F., Tamaki, R., Nomura, J., Miyoka, H. and Kitamura, T. (1996) Validation and reliability of a Japanese version of the EPDS. Archives of Psychiatrics Diagnosis and Clinical Evaluation, 7, 525533.

[15] Spielberger, C.D. (1983) State trait anxiety inventory for adults. The manual. Mind Garden, California.

[16] Maxson, P.J., Edwards, S.E., Ingram, A. and Miranda, M.L. (2012) Psychosocial differences between smokers and non-smokers during pregnancy. Addictive Behaviors, 37, 153-159. doi:10.1016/j.addbeh.2011.08.011

[17] Health and Nutrition Research (2012) National health and nutrition research of 2013. Daiich Shuppan Co., Tokyo. (in Japanese)

[18] Levine, M.D., Marcus, M.D., Kalarchian, M.A., Houck, P.R. and Cheng, Y. (2010) Weight concerns, mood, and postpartum smoking relapse. American Journal of Preventive Medicine. 39, 345-351.

doi:10.1016/j.amepre.2010.05.023

[19] Munafo', M.R., Heron, J. and Araya, R. (2008) Smoking patterns during pregnancy and postnatal period and depressive symptoms. Nicotine and Tobacco Research, 10 1609-1620. doi:10.1080/14622200802412895

[20] Neuman, A., Hohmann, C., Orsini, N., Pershagen, G., Eller, E., Kjear, H.F., Gehring, U., Granell, R., Henderson, J., Heinrich, J., Lau, S., Nieuwenhuijsen, M. Sunyer, J., Tischer, C., Torrent, M., Wahn, U., Wijga, A.H., Wickman, M., Keil, T., Bergstom, A. and ENRIECO Consortium (2012) Maternal smoking in pregnancy and asthma in preschool children: A pooled analysis of eight cohorts. American Journal Respiratory Critical Care Medicine, 186, 1037-1043. doi:10.1164/rccm.201203-05010C

[21] Carey, M.P., Kalra, D.L., Carey, K.B., Halperin, S. and 
Richards, C.S. (1993) Stress and unaided smoking cessation: A prospective investigation. Journal of Consulting and Clinical Psychology, 61, 831-838. doi:10.1037/0022-006X.61.5.831

[22] Weaver, K., Campbell, R., Mermelstein, R. and Wakschlag, L. (2008) Pregnancy smoking in context: The influence of multiple levels of stress. Nicotine and Tobacco Research, 10, 1065-1073. doi:10.1080/14622200802087564

[23] Tselebis, A., Papaleftheris, E., Balis, E., Theotoka, I. and Ilias, I. (2003) Smoking related to anxiety and depression in Greek medical staff. Psychological Reports, 92, 529532. doi:10.2466/pr0.2003.92.2.529

[24] Coleman, T., Chamberiain, C., Davey, M.A., Cooper, S.E. and Leonardi-Bee, J. (2012) Pharmacological interventions for promoting smoking cessation during pregnancy. The Cochrane Database of Systematic Reviews, CD 010078. doi:10.1002/14651858.CD010078

[25] Stead, L.F., Perera, R, Bullen, C., Mant, D., HartmannBoycr, J. and Lancaster, T. (2012) Nicotine replacement therapy for smoking cessation. Cochrane Database of Systematic Reviews, 1, CD000146. doi:10.1002/14651858.CD000146.pub4

[26] Duckwrth, A.L. and Chertok, I.R. (2012) Review of perinatal partner-focused smoking cessation interventions. MCN. The American Journal of Maternal Child Nursing, 37, 174-181. doi:10.1097/NMC.0b013e31824921b4

[27] Suzuki, J., Kikuma, H., Kawaminami, K. and Shima, M.
(2005) Predictors of smoking cessation during pregnancy among the women of Yamato and Ayase municipalities in Japan. Public Health, 119, 679-685. doi:10.1016/i.puhe.2004.10.014

[28] Miyatake, N., Nishii, K. and Numata, T. (2011) Relationship between work style and cigarette smoking in Japanese workers. Health, 3, 537-541. doi:10.4236/health.2011.39090

[29] Kaneko, A., Kaneita, Y., Yokohama, E., Miyake, T., Harano, S., Suzuki, K., Ibuka, E., Yamaki, T., Kakajima, H. and Ohida, T. (2008) Smoking trends before, during, and after pregnancy among women and their spouses. Pediatrics International: Official Journal of the Japan Pediatric Society, 50, 367-375. doi:10.1111/j.1442-200X.2008.02582.X

[30] Parackal, S., Ferguson, E. and Harraway, J. (2007) Alcohol and tobacco consumption among $6-24$ months postpartum New Zealand women. Maternal \&Child Nutrition, 3, 40-51. doi:10.1111/j.1740-8709.2007.00064.x

[31] Wiesbeck, G.A., Kuhl, H.C., Yaldizli, O. and Wurst, F.M. (2008) Tobacco smoking and depression-results from the WHO/ISBRA study. Neuropsychobiology, 57, 26-31. doi:10.1159/000123119

[32] Arai, Y., Hosokawa, T., Fukao, A., Izumi, Y. and Hisamichi, S. (1997) Smoking behavior and personality: A population-based study in Japan. Addiction, 92, 1023-1033. doi:10.1111/j.1360-0443.1997.tb02982.x 